\title{
The impact of iridium on the stability of platinum on carbon thin-film model electrodes
}

\author{
Maria Wesselmark ${ }^{\mathrm{a}, 2}$, Björn Wickman ${ }^{\mathrm{b}}$, Carina Lagergren ${ }^{\mathrm{a}, *, 1}$, Göran Lindbergh $^{\mathrm{a}, 1}$ \\ a Applied Electrochemistry, School of Chemical Science and Engineering, KTH Royal Institute of Technology, SE-100 44 Stockholm, Sweden \\ b Department of Applied Physics, Competence Centre for Catalysis, Chalmers University of Technology, SE-412 96 Göteborg, Sweden
}

\section{A R T I C L E I N F O}

\section{Article history:}

Received 7 March 2013

Received in revised form 11 July 2013

Accepted 13 July 2013

Available online $\mathrm{xxx}$

\section{Keywords:}

Fuel cell

PEMFC

Oxygen reduction

Iridium oxide

Platinum

\begin{abstract}
A B S T R A C T
Increasing the stability and lifetime of the electrodes is one of the most important factors in order to realise a large scale use of polymer electrolyte membrane fuel cells (PEMFC). By using well-defined thin-film model electrodes, the stability of Pt and Pt on Ir were examined as cathode catalysts in a single cell PEMFC setup. The electrodes were fabricated by evaporating thin layers of Pt and Pt on Ir onto the microporous layer of a gas diffusion layer. The amount of Pt deposited was equivalent to $3 \mathrm{~nm}$ (about $6.3 \mu \mathrm{g} \mathrm{cm}{ }^{-2}$ ) and the amount of Ir was varied between $1.5 \mathrm{~nm}$ and $20 \mathrm{~nm}$ (between $3.4 \mu \mathrm{g} \mathrm{cm}^{-2}$ and $45.3 \mu \mathrm{g} \mathrm{cm}^{-2}$ ). All samples with Ir showed an increased stability over samples with sole Pt during cyclic corrosion test between $0.6 \mathrm{~V}$ and $1.2 \mathrm{~V}$ vs. the reversible hydrogen electrode. For thin layers of Ir, the initial activity for the oxygen reduction reaction was equal to or superior to that of sole Pt but for thicker Ir films it was somewhat lower. Hydrogen underpotential deposition and CO stripping were used to estimate the electrochemical surface area during the experiments and physical characterisation using scanning electron microscopy and X-ray photoelectron spectroscopy were used to determine the structure of the samples. The results suggest that Ir can stabilise Pt in the cathode electrode.
\end{abstract}

(C) 2013 Elsevier Ltd. All rights reserved.

\section{Introduction}

Today, high amounts of Pt catalyst are needed on the cathode in the polymer electrolyte fuel cell due to the sluggish oxygen reduction reaction. In addition, the loss of electrochemically active surface area in the catalyst layer causes a considerable performance loss over time. The degradation is more severe on the cathode than on the anode, partly due to carbon corrosion, and it is therefore important to find a way to improve the activity and stability of the cathode catalyst layer [1].

By using alternative materials as support for Pt, an enhanced activity and stability may be obtained [2-8]. An increased ORR activity of a non-alloy, or catalyst on support, can be explained by a spill-over mechanism of reactants or intermediates between the two materials or by the adlineation mechanism, where new sites with enhanced activity is created in the interfacial area between the two materials $[2,3,6]$. The difference between Pt on a support and a Pt alloy are sometimes subtle and the effects of Pt on a

\footnotetext{
* Corresponding author

E-mail address: carinal@kth.se (C. Lagergren).

1 ISE member.

2 Present adress: Intertek Semko AB, Torhamnsgatan 43, Box 1103, SE-164 22 Kista, Sweden.
}

support could be similar to the ones of an alloy. Recently there has been a strong development of Pt monolayer catalysts, with a very good Pt utilisation, improved activity and good stability [4]. The improved activity may be related to a change in the Pt-Pt distance, changes in the electron structure or an increased repulsion of $\mathrm{OH}_{\mathrm{ad}}$ on $\mathrm{Pt}[4,7,8]$. Metal oxides are generally rather stable in the fuel cell environment and have been investigated both as support and combined with Pt in the catalyst layer in order to increase the stability of the electrode and the activity for ORR [9-18]. The advantage of using a metal oxide as catalyst support instead of carbon is a higher oxidation resistance, but additional effects such as better adhesion of the Pt and higher ORR activity on the alternative support material could also be achieved.

Ir (or Ir oxide) is a very good catalyst for the oxygen evolution reaction (OER) in acidic solution [19] and is therefore often added to the Pt catalyst of the cathode in unitised regenerative fuel cells [20-30]. Higher Ir content improves the OER whereas too high amounts of Ir have a negative effect on the ORR [26,27]. Due to the high potentials obtained during electrolysis of water in the regenerative mode it is important with an electrode which is stable at those potentials. With Ti and Ir oxide as gas diffusion layer, an improved stability of the catalyst layer has been achieved [30]. Improved stability as well as higher activity for oxygen reduction was predicted in DFT calculations by Balbuena et al. [31] of ternary alloys with Pt, Ir and Co or Cr. The improvements were 
ascribed to the stability of Ir and a lower binding energy of OH. $\mathrm{IrO}_{2}$ as well as Ir dendrites were shown by $\mathrm{Oh}$ et al. to inhibit carbon corrosion in the catalyst layer by eliminating water around the carbon support [32]. Pt-Ir alloys [33-36] or mixed monolayers of Pt-Ir on Pd nanoparticles [37] have also shown enhanced catalytic activity for oxygen reduction. The Ir was also in those studies suggested to weaken the adsorption strength of $\mathrm{OH}$, which lowers the $\mathrm{OH}-$ coverage and facilitates the ORR [34,35,37]. Pt deposited on Ir oxide has shown enhanced catalytic activity for ORR compared to Pt [10]. Furthermore, Ir oxide alone has shown some activity for oxygen reduction when deposited as nanoparticles on a carbon support in the cathode of a polymer electrolyte fuel cell $[38,39]$. The studies mentioned above have all shown various beneficial effects on the cathode when Ir is included. Nevertheless, Ir is a noble metal, almost as expensive as Pt, and the improvements need to be extensive in order to motivate the use of Ir in fuel cell catalysts.

In a previous study, thin-film model electrodes were used for investigating the impact of different metal oxides on the stability and activity of Pt in the cathode in a PEMFC [40]. This type of model electrode can be seen as a two-dimensional, thin slice of a porous electrode with a three-phase interface of catalyst, support material and Nafion. The model electrodes are well defined and fast to fabricate, in contrast to conventional porous electrodes which need synthesising of supported catalyst particles as well as optimisation of the electrode structure before the catalytic activity can be tested in a fuel cell. In addition, it is very difficult to keep the structure of porous electrodes constant when examining different materials. The heterogeneous and complex structures of the porous electrodes also make it difficult to assess the true catalytic activity without including effects from local mass transport, potential and humidity conditions. Another advantage of the model electrode is the low catalyst loading, resulting in low currents, which give low iR-losses, and limited water and heat production.

In the present study, the interaction between Pt and Ir is examined. Model thin film electrodes with Pt deposited on a thin metallic layer of Ir was prepared. It is however well known that Ir can form irreversible thick layers of Ir oxides when cycled to higher potentials $[41,42]$, which may influence the properties. The impact of different amounts of Ir on the activity and long-term stability of these electrodes is examined in a fuel cell.

\section{Experimental}

\subsection{Model electrode preparation}

CARBEL CL gas diffusion layers (GDL) were purchased from Gore Technologies and the surface was cleaned with flowing nitrogen gas prior to film deposition. Thin catalyst films were deposited by thermal evaporation in vacuum (AVAC HVC600, at about $10^{-6}$ mbar). Ir and Pt were evaporated on to the GDL at controlled thicknesses, measured with a quartz crystal microbalance sensor located in the chamber. The amount of Pt deposited was equivalent to $3 \mathrm{~nm}$ (about $6.3 \mu \mathrm{g} \mathrm{cm}^{-2}$ ) and the amount of Ir was varied between $1.5 \mathrm{~nm}$ and $20 \mathrm{~nm}$ (between $3.4 \mu \mathrm{g} \mathrm{cm}^{-2}$ and $45.3 \mu \mathrm{g} \mathrm{cm}^{-2}$ ). The samples are named according to the amount of material in the following way; yPtzIr, represents a sample with $y \mathrm{~nm}$ of Pt deposited on top of $z$ $\mathrm{nm}$ of Ir, which in turn was deposited on GDL.

\subsection{Electrode morphology and chemistry characterisation}

The thin film catalysts morphology was characterised by scanning electron microscopy (SEM, Leo Ultra 55 FEG) operating at $10 \mathrm{kV}$ in the secondary electron mode. Chemical characterisation was performed using X-ray photoelectron spectroscopy (XPS, Perkin Elmer
PHI 5000 C ESCA system) using monochromatic $\mathrm{Al} \mathrm{K \alpha}$ radiation and a $45^{\circ}$ take-off angle [43].

\subsection{Electrochemical evaluation}

Circular disks with a diameter of $14 \mathrm{~mm}$ were punched out from the thin film electrodes and used as working electrodes (WE) in electrochemical evaluation in fuel cell measurements. Before the preparation of the membrane electrode assembly (MEA) some of the samples were sprayed with a Nafion solution. This was done with $2 \%$ Nafion in isopropanol and approximately ten times with drying in between until the surface became shiny of a thin layer of Nafion. In order to prepare MEAs, the thin model electrode disks were placed onto $45 \times 45 \mathrm{~mm}$ pieces of Nafion ${ }^{\mathrm{TM}} 115$ membranes (Nafion 115, Aldrich). The membranes had previously been cleaned by boiling in $3 \% \mathrm{H}_{2} \mathrm{O}_{2}$ for $1 \mathrm{~h}$, in $0.1 \mathrm{M} \mathrm{H}_{2} \mathrm{SO}_{4}$ for $1 \mathrm{~h}$ and finally in three successive baths of Milli-Q water for $1 \mathrm{~h}$ each after which the membranes were dried in an oven at $80^{\circ} \mathrm{C}$ overnight. Commercial porous ELAT electrodes (30\% Pt on Vulcan XC-72) with a loading of $0.5 \mathrm{mg} \mathrm{Pt} \mathrm{cm} \mathrm{cm}^{-2}$ were placed on the counter side of the membrane and used as combined counter and reference electrode (CE/RE). The MEAs (thin film electrode on GDL + membrane + ELAT electrode) were hot pressed at $135^{\circ} \mathrm{C}$ for $30 \mathrm{~s}$ at $1 \mathrm{MPa}$. The MEA was mounted in a laboratory PEEK (polyether-etherketone) fuel cell, described elsewhere [44], with cylindrical, $30 \mathrm{~mm}$ in diameter, graphite current collector with spirally formed gas channels and a clamping force over the current collectors of $380 \mathrm{~N}$.

For the standard case, if nothing else is mentioned, the gases were humidified in heated humidifiers (Fuel Cell Technologies Inc.) held at $77^{\circ} \mathrm{C}$, resulting in $90 \%$ relative humidity (RH) in the fuel cell with a cell temperature of $80^{\circ} \mathrm{C}$. Cyclic sweeps were performed with $\mathrm{O}_{2}$ or $\mathrm{N}_{2}$ on the WE and $5 \% \mathrm{H}_{2}$ in $\mathrm{Ar}$ at the CE/RE fed in excess at $1 \mathrm{ml} \mathrm{s}^{-1}$. The very low loading on the $\mathrm{WE}$, compared to the porous $\mathrm{CE} / \mathrm{RE}$, made it possible to use $5 \% \mathrm{H}_{2}$ in Ar which avoids crossover of hydrogen to the WE. The CE/RE was also assumed not to be polarised due to the low current density. All measured potentials from the fuel cell tests are referred to the reversible hydrogen electrode (RHE) and the potentials have therefore been corrected for the $45.5 \mathrm{mV}$ shift due to the lower hydrogen partial pressure ( $5 \%$ $\mathrm{H}_{2}$ in $\mathrm{Ar}$ ).

After $2 \mathrm{~h}$ of constant gas flow at the correct temperature, the electrochemical measurements always started with cyclic sweeps in nitrogen to get a description of the surface processes on the electrode. This was followed by an activation procedure by 2000 cycles at $20 \mathrm{mV} \mathrm{s}^{-1}$ between $0.6 \mathrm{~V}$ and $0.9 \mathrm{~V}$ vs. RHE in oxygen after which further measurements were performed.

CO-stripping curves were recorded in the potential window between $0.05 \mathrm{~V}$ and $1.2 \mathrm{~V}$, at a sweep rate of $20 \mathrm{mV} \mathrm{s}^{-1}$. After a cycle in humidified $\mathrm{N}_{2}$ gas, the potential scan was stopped at $0.15 \mathrm{~V}$ and the gas flow shifted to CO-containing gas ( $2 \% \mathrm{CO}$ balanced with $\mathrm{Ar}$ ) for $\mathrm{CO}$ adsorption during $2 \mathrm{~min}$. Thereafter the inlet gas was shifted back to nitrogen for $5 \mathrm{~min}$, to flush out remaining $\mathrm{CO}$ in the cell, before subsequent stripping.

\section{Results and discussion}

\subsection{Materials characterisation}

SEM and XPS were employed to characterise the structure of the thin-film model electrodes prior to the electrochemical evaluation. Fig. 1 shows SEM images of 3Pt, 3Ir, 3Pt3Ir, 3Pt20Ir, and 3Pt1.5Ir evaporated on GDL. In agreement with what has been shown before, evaporating $3 \mathrm{~nm}$ of Pt results in a non-continuous Pt film of separated nanoparticles, roughly $3-6 \mathrm{~nm}$ in size on the exposed area of the GDL [39]. The structure of $3 \mathrm{~nm}$ Ir film on GDL is 

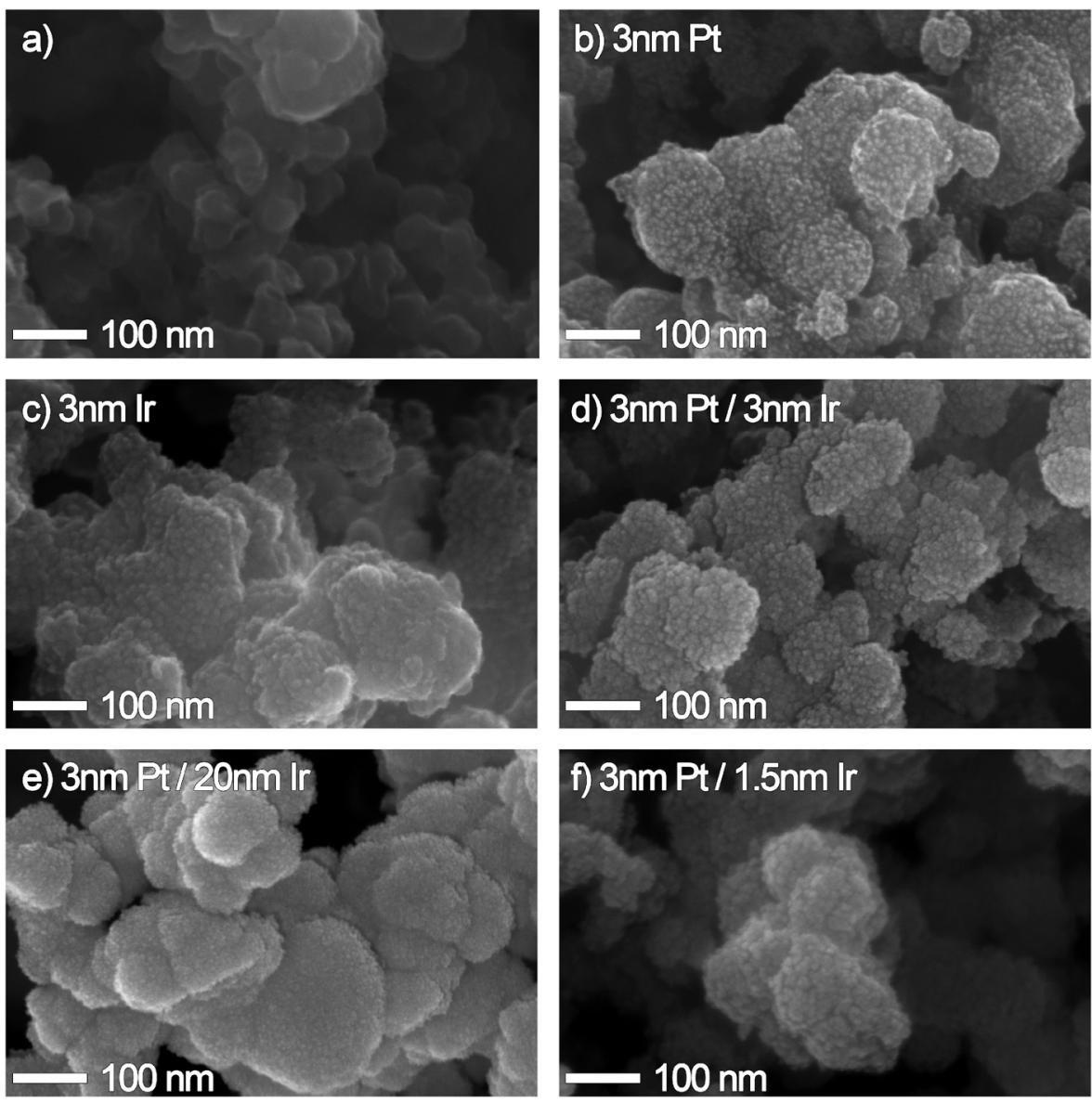

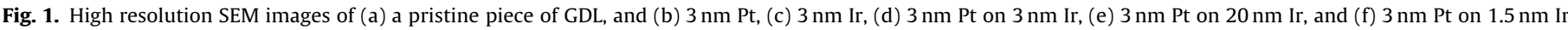
thin-film model electrodes deposited on GDL.

very similar to that of the 3Pt sample, with isolated particles. For the sample with $3 \mathrm{~nm}$ Pt on $3 \mathrm{~nm}$ Ir, it looks like there are still isolated particles, but they are larger than for the samples with only $3 \mathrm{~nm}$ of metal evaporated and some particles appear to have coalesced. $3 \mathrm{~nm}$ Pt on $1.5 \mathrm{~nm}$ Ir is essentially very similar to the 3Pt3Ir sample. Finally, a $20 \mathrm{~nm}$ thick Ir film cover the exposed carbon surface with a continuous layer. It is difficult to distinguish between Pt and Ir in the SEM images, thus it is hard to say much about the structure of the individual metals in the combined samples. However, some information about this can be obtained from the XPS data.

Fig. 2a shows overview spectra for 3Pt, 3Ir, and 3Pt3Ir. The (4f) core level peaks for Pt and Ir for all samples are shown in Fig. 2b and c, respectively. From the overview spectra (Fig. 2a) it can be noticed that the Ir signals from the 3Pt3Ir sample is very low which indicates that Pt effectively covers most of the Ir. The same was observed for the 3Pt1.5Ir sample. The atomic distribution of Pt vs. Ir was found to be about $91 \%$ and $94 \% \mathrm{Pt} \mathrm{(} 9 \%$ and $6 \%$ Ir) for 3Pt 3 Ir and 3Pt1.5Ir, respectively. Both Pt and Ir were found to be in metallic form after fabrication, with the $\left(4 \mathrm{f}_{7 / 2}\right)$ peak located around $71.5 \mathrm{eV}$ and $61.3 \mathrm{eV}$, respectively.

\subsection{Electrochemical results}

Fig. 3 displays polarisation curves in oxygen for 3Pt and 3Pt3Ir directly after activation, after 1000 degradation cycles, and for 3Pt3Ir, also after 2000 cycles. It can be seen that the polarisation curves of 3Pt and 3Pt3Ir are similar after the activation. The extra layer of $3 \mathrm{~nm}$ Ir does not have any effect on the oxygen reduction activity of the electrode. When the electrodes are cycled between
$0.6 \mathrm{~V}$ and $1.2 \mathrm{~V}$ the performance decreases much faster on 3Pt than on 3Pt3Ir. After 1000 cycles, 3Pt3Ir performs much better than 3Pt and first after a further 1000 cycles, 3Pt3Ir performs similar to what 3Pt did after only 1000 cycles.

In a previous study using thin-film model electrodes, we showed that the loss in ORR performance corresponded well to the loss of electrochemically active surface area estimated by the charge of the hydrogen under potential deposition $\left(\mathrm{H}_{\mathrm{UPD}}\right)$ determined from cyclic voltammograms [40]. Fig. 4 shows the cyclic voltammograms corresponding to the polarisation curves in Fig. 3. The cyclic voltammogram of 3Pt displays features characteristic for Pt, with well-defined hydrogen adsorption/desorption peaks and Ptoxide formation/reduction peaks. In Table 1, it can be seen that the electrochemically active surface area (ECSA, here presented normalised to the projected surface area) has decreased significantly after 1000 degradation cycles, from 0.18 to $0.05 \mathrm{~cm}^{2} \mathrm{Pt} \mathrm{cm}^{-2}$, calculated from the $\mathrm{H}_{\mathrm{UPD}}$ charge. This corresponds quite well to the loss in performance seen in the polarisation curves, see Fig. 3 and

Table 1

Electrochemically active surface area (ECSA) estimated by the $\mathrm{H}_{\mathrm{UPD}}$ charges from the cyclic voltammograms in Fig. 4 normalised to the projected area of the samples and current density at $0.7 \mathrm{~V}$ in Fig. 3.

\begin{tabular}{|c|c|c|c|c|}
\hline \multirow[t]{2}{*}{ Sample } & \multicolumn{2}{|c|}{$\begin{array}{l}\text { Pt surface area factor/ } \\
\mathrm{cm}^{2} \mathrm{Pt} \mathrm{cm}^{-2}\end{array}$} & \multicolumn{2}{|c|}{$j_{0.7 \mathrm{v}} / 10^{-3} / \mathrm{Acm}^{-2}$} \\
\hline & $3 \mathrm{Pt}$ & 3Pt3Ir & $3 \mathrm{Pt}$ & $3 \mathrm{Pt} 3 \mathrm{Ir}$ \\
\hline Activated & 0.18 & 0.11 & 3.0 & 3.0 \\
\hline 1000 cycles & 0.05 & 0.11 & 1.3 & 2.2 \\
\hline 2000 cycles & - & 0.06 & - & 1.3 \\
\hline
\end{tabular}



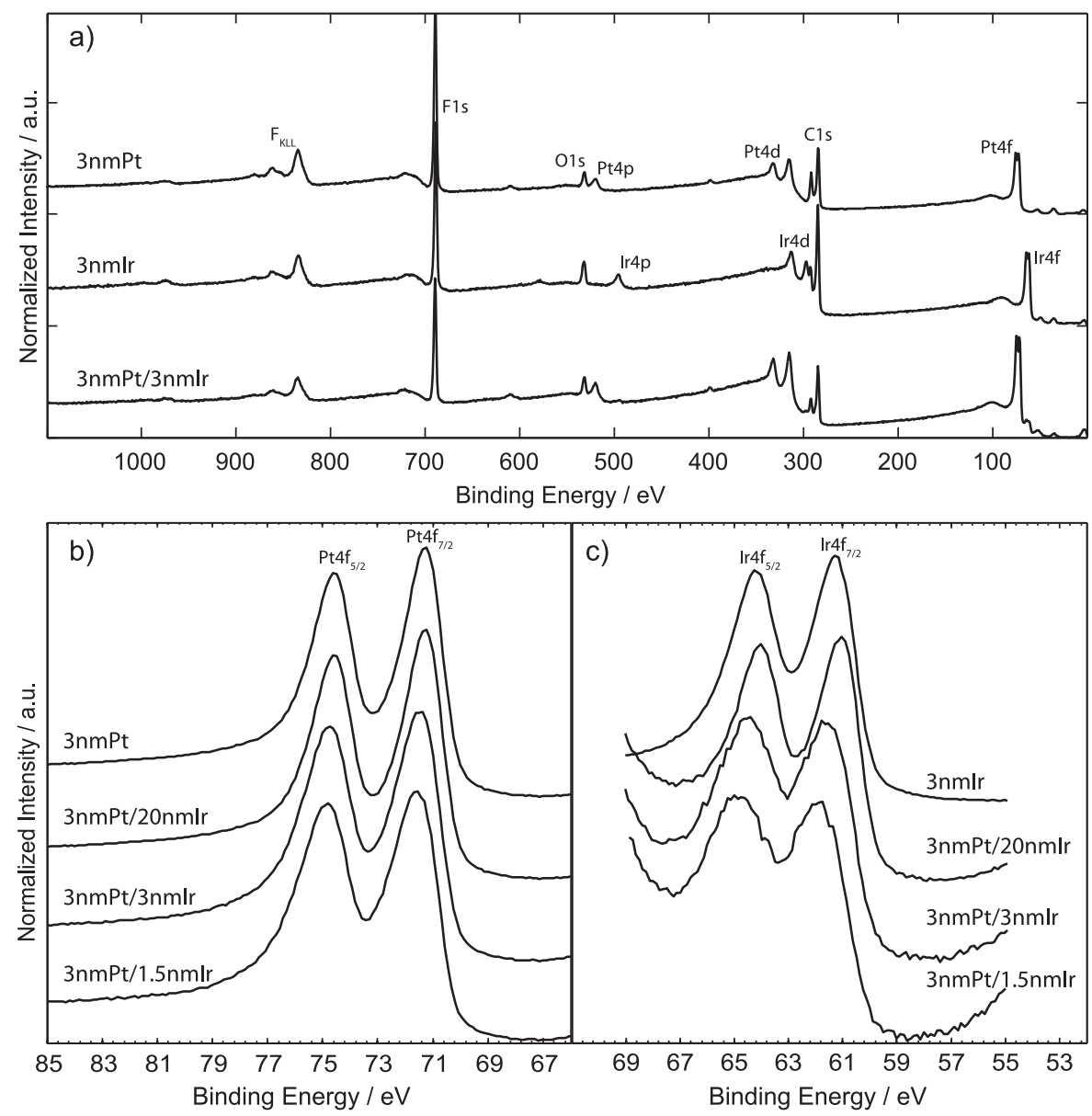

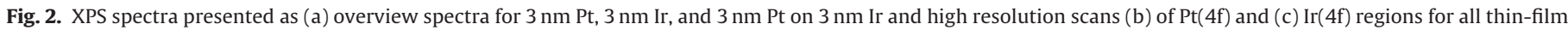
samples deposited on GDL.

Table 1 . The cyclic voltammograms of 3Pt3Ir display similar hydrogen adsorption/desorption peaks as 3Pt whereas the response in the oxide formation region is quite different from 3Pt. The initial $\mathrm{H}_{\mathrm{UPD}}$ charge of $3 \mathrm{Pt} 3 \mathrm{Ir}$ is however lower than for 3Pt. The response at higher potentials, in the oxide formation region, is most likely due to an overlap of the Pt-oxide formation/reduction and the response of Ir. During the potential cycling of the electrode in the activation procedure, a hydrous Ir oxide layer is most likely created, similar to

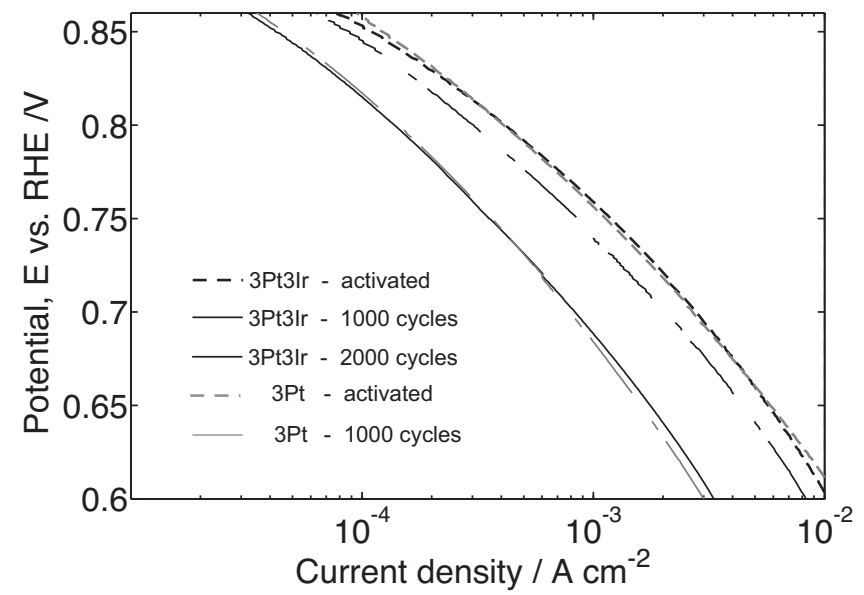

Fig. 3. Polarisation curves in oxygen for 3Pt and 3Pt3Ir, activated and after 1000 and 2000 cycles between $0.6 \mathrm{~V}$ and $1.2 \mathrm{~V}$ vs. RHE. Cell temperature $80^{\circ} \mathrm{C}$, relative humidity $90 \%$, scan rate $20 \mathrm{mV} \mathrm{s}^{-1}$. what has been found previously in literature $[29,45,46]$. The high oxidation and reduction charges around $1 \mathrm{~V}$ may then be attributed to the change of oxidation state of Ir within the oxide, which has been described in literature $[29,41,42,47-49]$. When the electrode is cycled further, the charges in the oxide region decrease significantly. However, the $\mathrm{H}_{\mathrm{UPD}}$ charge does not decrease to the same extent. When calculating the electrochemically active surface area from the $\mathrm{H}_{\mathrm{UPD}}$ it is actually the same before and after 1000 degradation cycles, $0.11 \mathrm{~cm}^{2} \mathrm{Pt}_{\mathrm{cm}}^{-2}$, whereas it is reduced about $50 \%$, to $0.06 \mathrm{~cm}^{2}{ }_{\mathrm{Pt}} \mathrm{cm}^{-2}$, after 2000 cycles. For 3Pt3Ir, the $\mathrm{H}_{\mathrm{UPD}}$ area does not directly correspond to the activity for oxygen reduction in the polarisation curve, see Figs. 3 and 4 and Table 1. In the literature, varying results can be found regarding the $\mathrm{H}_{\text {UPD }}$ region of Ir and Ir oxide. Upon cycling (i.e. when creating Ir oxide) no or just a very small $H_{U P D}$ charge was observed in some studies [45,47,50], while a decreasing, but clearly resolved, $\mathrm{H}_{\mathrm{UPD}}$ charge was found by others $[29,42,49]$. This behaviour may be attributed to the low conductivity of the reduced form of Ir oxide [42]. Bock et al. have on the other hand seen clearly resolved $H_{\text {UPD }}$ charges [46]. The thin model electrodes used in this work have both Pt and Ir and thus it can be noted that the electrochemically active surface area determined by the $\mathrm{H}_{\text {UPD }}$ charge does not seem to directly correspond to the activity for oxygen reduction in the polarisation curves.

For the thin model electrodes used in Figs. 3 and 4, the only proton conducting media is the membrane that is pressed against the catalyst. In order to improve the proton conductivity and increase the electrochemically active surface, a Nafion solution was sprayed onto the electrodes before hot pressing the MEA. The polarisation curves of Nafion covered 3Pt and 3Pt3Ir are shown in Fig. 5. When 


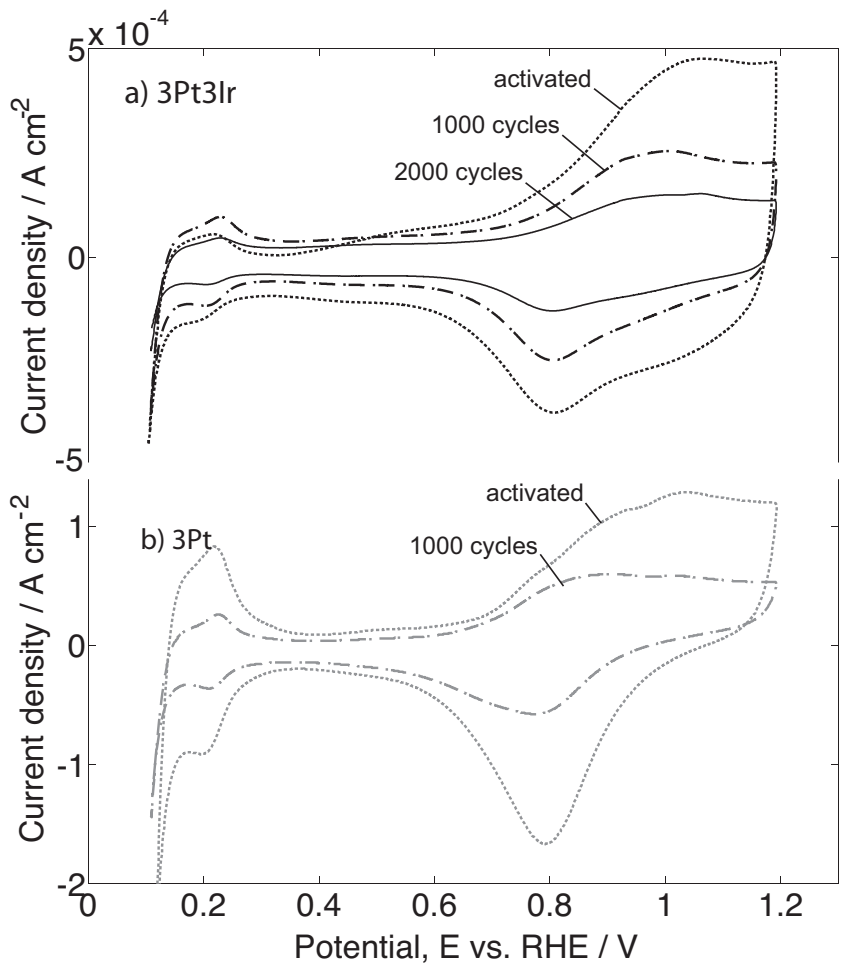

Fig. 4. Cyclic voltammograms in nitrogen at $100 \mathrm{mV} \mathrm{s}^{-1}$ on (a) 3Pt3Ir and (b) 3Pt. Cell temperature $80^{\circ} \mathrm{C}$, relative humidity $90 \%$.

comparing the initial polarisation curves of the activated Nafion covered electrodes in Fig. 5 with the uncovered electrodes in Fig. 3, it can be seen that the performance has become much better by spraying Nafion onto the electrode for both 3Pt and 3Pt3Ir. The improvement is most likely related to an increase in the electrochemically active surface area. The extra Nafion layer may however have affected the mass transport of reactants to the active sites to some extent, giving rise to slightly steeper polarisation curves at higher current densities. When comparing the Nafion covered electrodes in Fig. 5, the initial activity of 3Pt3Ir is slightly higher than the activity of 3Pt. In addition, the loss in performance caused by the cycling is also clearly lower on 3Pt3Ir when compared to 3Pt. This trend is in good agreement with the results from the samples without Nafion.

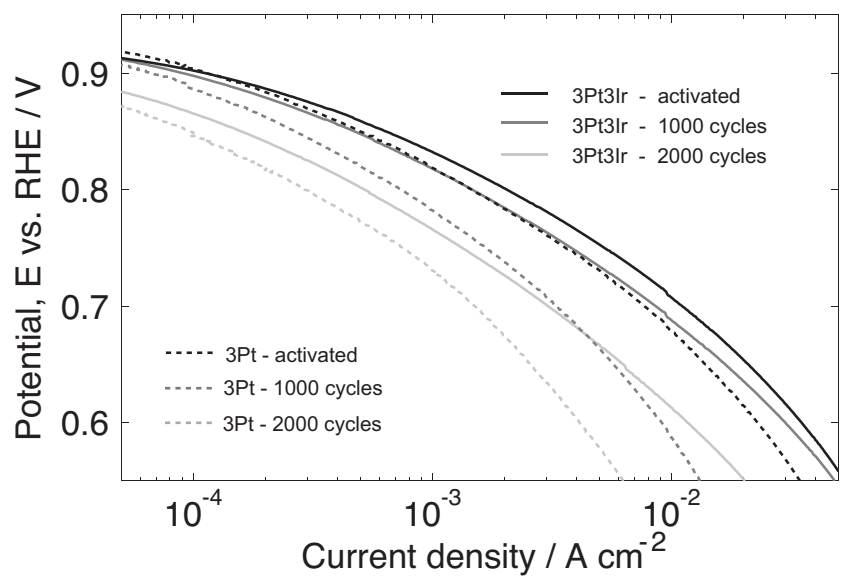

Fig. 5. Polarisation curves in oxygen of Nafion coated 3Pt and 3Pt3Ir, activated and after each following degradation of 1000 cycles between $0.6 \mathrm{~V}$ and $1.2 \mathrm{~V}$ vs. RHE. Cell temperature $80^{\circ} \mathrm{C}$, relative humidity $90 \%$, scan rate $20 \mathrm{mV} \mathrm{s}^{-1}$.
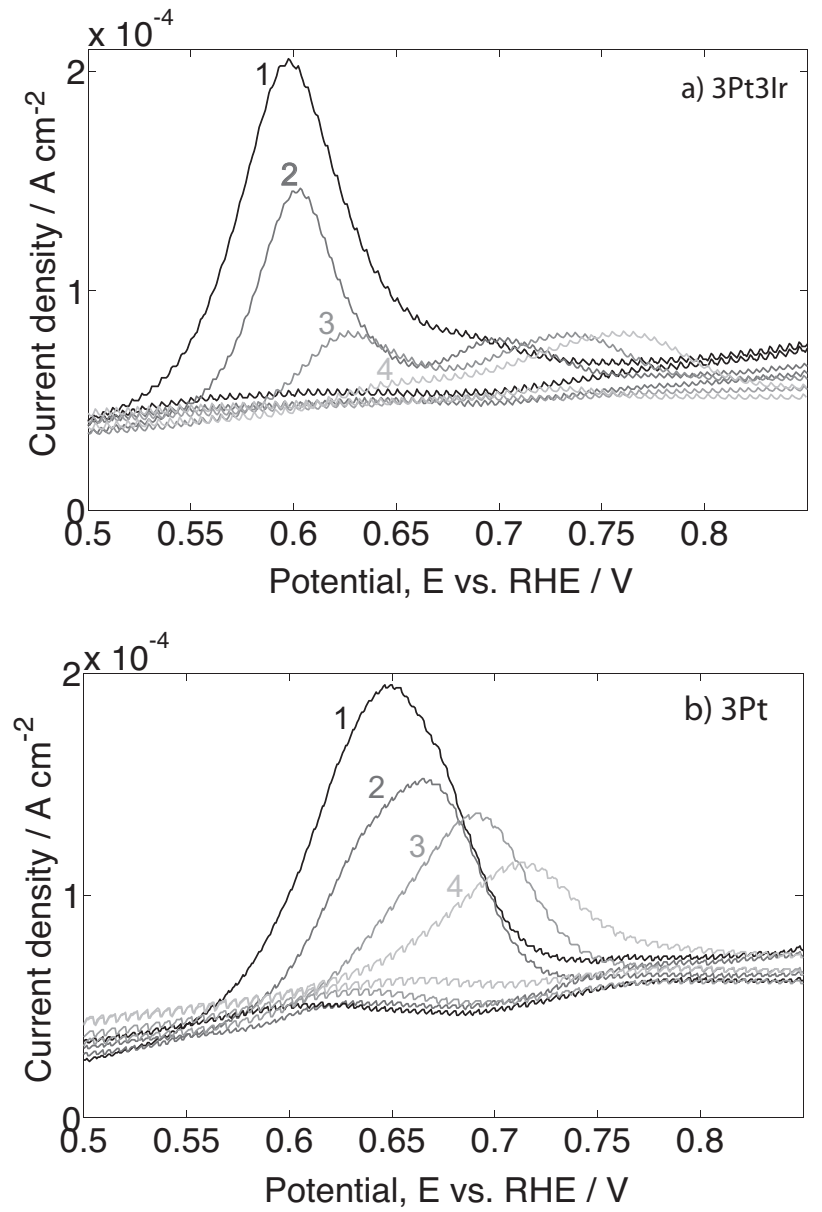

Fig. 6. CO-stripping of (a) 3Pt3Ir and (b) 3Pt, (1) activated and after (2) 1000, (3) 2000 and (4) 3000 potential cycles between $0.6 \mathrm{~V}$ and $1.2 \mathrm{~V}$ vs. RHE. Cell temperature $80{ }^{\circ} \mathrm{C}$, relative humidity $90 \%$, scan rate $20 \mathrm{mV} \mathrm{s}^{-1}$.

Since the $\mathrm{H}_{\text {UPD }}$ charge was shown to not fully correlate with the oxygen reduction activity in the PtIr samples, CO-stripping was performed in addition to the cyclic voltammograms after each period of 1000 degradation cycles, in order to determine the electrochemically active surface area and further characterise the degradation. The CO-stripping results are shown in Fig. 6. For 3Pt3Ir, the oxidation starts at lower potentials than for $3 \mathrm{Pt}$, around $0.5 \mathrm{~V}$ compared to $0.55 \mathrm{~V}$ vs. RHE. The charge below the CO oxidation peak of the activated samples is quite similar for Pt and PtIr, with $680 \mu \mathrm{C}$ and $600 \mu \mathrm{C}$ respectively. Despite the slightly higher $\mathrm{CO}$ oxidation charge of 3Pt, 3Pt3Ir displays a higher activity for oxygen reduction (Fig. 5). The CO-stripping peak decreases with increasing number of degradation cycles, for both samples. However, the charge of the CO-stripping peak for 3Pt3Ir is decreasing faster than for $3 \mathrm{Pt}$ and does not seem to correlate very well to the performance in the polarisation curves. The correlation between $\mathrm{CO}$-stripping charge and activity in the polarisation curve is good for 3Pt, but it could be questioned if $\mathrm{CO}$ adsorption is an appropriate method to determine the electrochemically active surface of 3Pt3Ir. Even if there is no good correlation between the $\mathrm{CO}$ adsorption and electrochemically active surface area, there is a clear difference in the shape of the CO-stripping peak for Pt and PtIr. Chen et al. showed in their study that the $\mathrm{H}_{\text {UPD }}$ charges and the CO-stripping charges gave similar values for the electrochemically active surface area of electrodes with Pt deposited on Ir oxide, assuming linearly bonded CO [51]. However, for the 3Pt3Ir electrodes covered with Nafion used in this work, the $\mathrm{H}_{\text {UPD }}$ charges are very low which is similar to 

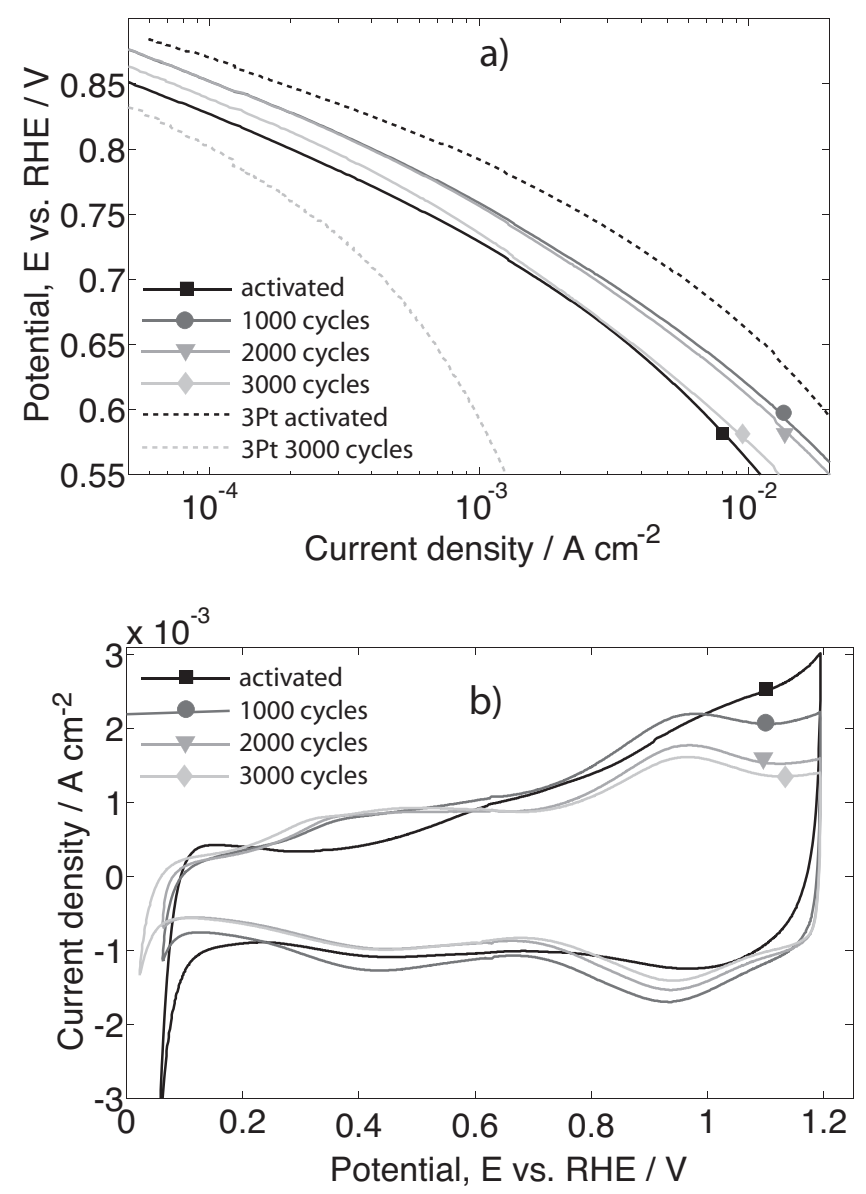

Fig. 7. $3 \mathrm{~nm}$ Pt on $20 \mathrm{~nm} \mathrm{Ir}$, (a) polarisation curves in $\mathrm{O}_{2}$ at $1 \mathrm{mV} \mathrm{s}^{-1}$ with $3 \mathrm{Pt}$ for comparison and (b) cyclic voltammograms in $\mathrm{N}_{2}$ at $100 \mathrm{mV} \mathrm{s}^{-1}$. Cell temperature $80^{\circ} \mathrm{C}$, relative humidity $90 \%$.

observations made by Slavcheva et al. where diminishing $\mathrm{H}_{\mathrm{UPD}}$ charges on sputtered electrodes with Pt and Ir oxide with increasing hydration of the Ir oxide layer was seen [29]. Others have shown that especially anodically formed Ir oxide films do not display any $\mathrm{H}_{\text {UPD }}$ charges $[47,50]$. No comparison with the $\mathrm{H}_{\text {UPD }}$ charges was therefore possible to make. For Pt on Ir oxide there is a decrease in the main peak and a growth of a second peak at higher potentials with increasing number of cycles. The onset of the $\mathrm{CO}$ oxidation is also shifted to higher potential for each 1000 cycle period. Pt does only display a decrease in the main peak which is also shifted to higher potentials, which is similar to observations made in another degradation study performed with Pt model catalysts [40].

The measurements made with 3Pt and 3Pt3Ir indicate that Ir may stabilise the electrodes. In order to better understand the role of Ir in the thin model electrodes, a thinner $(1.5 \mathrm{~nm})$ and a thicker $(20 \mathrm{~nm})$ Ir film, but constant amount of Pt ( $3 \mathrm{~nm}$ ) was studied electrochemically. This was done with electrodes covered with Nafion and the results are shown in Figs. 7 and 8 as polarisation curves and cyclic voltammograms of 3Pt20Ir and 3Pt1.5Ir. For 3Pt20Ir, the high amount of Ir resulted in a large contribution from the change of oxidation state of $\mathrm{Ir}$ in the polarisation curves at $20 \mathrm{mV} \mathrm{s}^{-1}$. The polarisation curves were therefore recorded at $1 \mathrm{mV} \mathrm{s}^{-1}$, in Figs. 7a and 8a. 3Pt20Ir does initially display a lower activity than 3 Pt for the oxygen reduction (Fig. 7a). However, after 1000 degradation cycles, the performance has improved and is rather stable. Not until after 3000 cycles does the performance fall below the initial values. When comparing the cyclic voltammograms of 3Pt20Ir after activation and after 1000 cycles in Fig. 7b, an increase can be
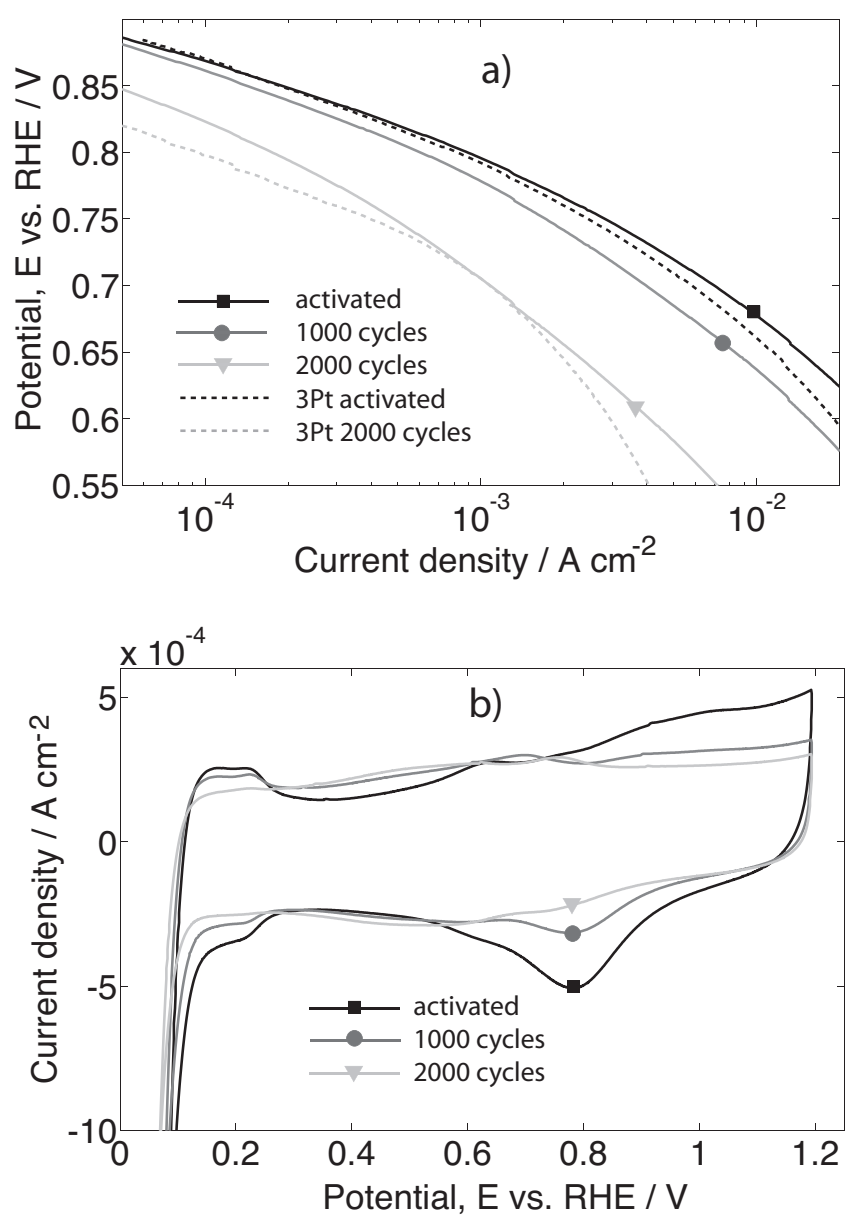

Fig. 8. $3 \mathrm{~nm}$ Pt on $1.5 \mathrm{~nm} \mathrm{Ir}$, (a) polarisation curves in $\mathrm{O}_{2}$ at $1 \mathrm{mV} \mathrm{s}^{-1}$ together with $3 \mathrm{Pt}$ for comparison and (b) cyclic voltammograms in $\mathrm{N}_{2}$ at $100 \mathrm{mV} \mathrm{s}^{-1}$. Cell temperature $80^{\circ} \mathrm{C}$, relative humidity $90 \%$.

seen in the peaks around $0.95 \mathrm{~V}$ vs. RHE, corresponding to the oxidation/reduction of Ir oxide. A decrease of the $\mathrm{H}_{\text {UPD }}$ charges can also be seen.

The increase in charges in the oxide region as well as the decrease in $\mathrm{H}_{\text {UPD }}$ charges is consistent with the growth of the hydrous Ir oxide layer upon cycling, according to literature [29]. The improvements seen in the polarisation curves could possibly be explained by an increased electrochemically active surface area due to the increased hydration and wetting of the active sites. When continuing cycling, a decrease in charges can be seen over the whole potential range in the cyclic voltammogram which may be related to a loss in electrochemically active surface area. Still, after 3000 cycles, the 3Pt20Ir performs much better than 3Pt. The electrode with $20 \mathrm{~nm}$ Ir may be considered to be more stable.

Measurements were also performed with 3Pt1.5Ir in order to compare the impact of a thick Ir layer with a thin. Due to the relatively high cost of Ir, it is also valuable to evaluate if also small amounts of Ir have a stabilising effect on the electrode. The initial activity of $3 \mathrm{Pt} 1.5 \mathrm{Ir}$ is slightly better than the activity of $3 \mathrm{Pt}$ (Fig. 8a). The performance of 3Pt1.5Ir is decreased when cycling the potential, but it still performs better than 3Pt after 2000 cycles. The good initial performance of 3Pt1.5Ir compared to 3Pt20Ir may be caused by a lower electronic resistance with a thinner layer of Ir. The cyclic voltammograms display similar features as a Pt electrode. A decrease in the $\mathrm{H}_{\text {UPD }}$ charges as well as in Pt-oxide reduction peak is seen when cycling the electrode. If there were any formation of an Ir oxide layer this was most likely already completed in the activation procedure and only a loss of electrochemically active surface 
area occurs when cycling the electrode. However, the loss of performance may be slightly slower for 3Pt1.5Ir than for 3Pt, but the effect is minor.

\section{Conclusions}

The impact of different amounts of Ir on the activity and stability of thin model electrodes with Pt was examined in a fuel cell. The stability of the electrodes with Ir was generally improved compared to sole Pt. However, the results were quite different with different amounts of Ir and in order to interpret the results properly, the formation of Ir oxide and also the hydration of the Ir oxide layer needs to be considered. When cycling the electrodes there is an increase in the charges around $0.95 \mathrm{~V}$, which corresponds well to values found in literature for the oxidation/reduction of Ir oxide. For a thicker film of Ir it takes longer time of cycling to obtain maximum amount of formed Ir oxide. The formation of hydrous Ir oxide seems to increase the electrochemically active surface area, possibly due to better wetting of the catalyst which in turn seems to increase the oxygen reduction activity. For a thicker layer of Ir the initial 2000 degradation cycles actually improve the performance, whereas for a thin layer of Ir only a loss in electrochemically active surface area and performance is seen during the degradation cycling. This could possibly be explained by the formation of a hydrous Ir oxide layer that is completed already during the activation for thinner layers of Ir whereas it for thicker layers of Ir, continues to grow also during the deactivation cycling. However, also 3Pt1.5Ir displays a better stability than 3Pt. The initial activity is also different for the electrodes with 1.5 and $3 \mathrm{~nm}$ and $20 \mathrm{~nm}$ Ir. The two former electrodes display slightly higher activities in the oxygen reduction polarisation curves than 3Pt, whereas 3Pt20Ir performs worse. This may be explained by the higher resistance of a thicker layer of a metal oxide. Due to the response of Ir oxide in the cyclic voltammogram, with reduced $\mathrm{H}_{\mathrm{UPD}}$ charges when activated as well as overlap of the peaks for oxidation/reduction of Ir oxide and Pt-oxide formation/reduction, it was difficult to get a proper measure of the electrochemically active surface area. The electrochemically active surface area determined by the CO-stripping charges did not seem to correspond very well to the activity seen in the polarisation curve for oxygen reduction. Ir has a stabilising effect on the thin model electrodes with Pt. A part of the effect may be related to an improved utilisation of the catalyst when the hydrous Ir oxide is being formed, but does not fully explain the improved stability of the electrodes with Ir.

\section{References}

[1] R. Borup, et al., Scientific aspects of polymer electrolyte fuel cell durability and degradation, Chem. Rev. 10 (2007) 3904.

[2] K. Hayek, R. Kramer, Z. Paal, Metal-support boundary sites in catalysis, Appl. Catal. A 162 (1997) 1

[3] W.C. Conner, J.L. Falconer, Spillover in Heterogeneous Catalysis, Chem. Rev. 95 (1995) 759

[4] W. Vielstich, H. Yokokawa, H.A. Gasteiger, Handbook of fuel cells: fundamentals technology and applications Advances in Electrocatalysis Materials, Diagnostics and Durability: Part 1, vol. 5, John Wiley \& Sons Ltd., 2009

[5] S. Sharma, B.G. Pollet, Support materials for PEMFC and DMFC electrocatalysis - A review, J. Power Sources 208 (2012) 96

[6] N.R. Elezovic, B.M. Babic, P. Ercius, V.R. Radmilovic, L.M. Vracar, N.V. Krstajic, Synthesis and characterization Pt nanocatalysts on tungsten based supports or oxygen reduction reaction, Appl. Catal. B: Environ. 125 (2012) 390

[7] S. Suzuki, T. Onodera, J. Kawaji, T. Mizukami, K. Yamaga, Effect of support materials on platinum lattice strain and its oxygen reduction activity, Appl. Catal. A: Gen. 427-428 (2012) 92

[8] C.K. Poh, S.H. Lim, Z. Tian, L. Lai, Y.P. Feng, Z. Shen, J. Lin, Pt-WxC nanocomposites as an efficient elelctrochemical catalyst for oxygen reduction reaction, Nano Energy (2012) http://dx.doi.org/10.1016/j.nanoen.2012.07.008

[9] J. Shim, C.R. Lee, H.K. Lee, J.S. Lee, E.J. Cairns, Electrochemical characteristics of Pt-WO $/ \mathrm{C}$ and Pt-TiO $/ \mathrm{C}$ electrocatalysts in a polymer electrolyte fuel cell, J. Power Sources 102 (2001) 172.
[10] K.-i. Ota, A. Ishihara, S. Mitsushima, K. Lee, Y. Suzuki, N. Horibe, T. Nakagawa, N. Kamiya, Improvement of cathode materials for polymer electrolyte fuel cell, J. New Mater. Electrochem. Syst. 8 (2005) 25.

[11] H. Chhina, S. Campbell, O. Kesler, Ex-situ evaluation of tungsten oxide as a catalyst support for proton exchange membrane fuel cells, J. Electrochem. Soc. 154 (2007) B533.

[12] T. Ioroi, H. Senoh, S.-I. Yamazaki, Z. Siroma, N. Fujiwara, K. Yasuda, Stability of corrosion-resistant magneli-phase Ti407-supported PEMFC catalysts at high potentials, J. Electrochem. Soc. 155 (2008) B321.

[13] G. Liu, H. Zhang, Y. Ma, $\mathrm{Pt}_{4} \mathrm{ZrO}_{2} / \mathrm{C}$ cathode catalyst with excellent durability for high temperature PEMFC based on $\mathrm{H}_{3} \mathrm{PO}_{4}$ doped PBI, Mater. Sci. Forum 561-565 (2007) 1589

[14] Y. Suzuki, A. Ishihara, S. Mitsushima, N. Kamiya, K.-I. Ota, Sulfated-zirconia as a support of Pt catalyst for polymer electrolyte fuel cells, Electrochem. Solid-State Lett. 10 (2007) B105.

[15] J. Tian, G. Sun, M. Cai, Q. Mao, Q. Xin, $\mathrm{PtTiO}_{x} / \mathrm{OC}$ electrocatalysts with improved durability inH-2/O-2 PEMFCs without external humidification, J. Electrochem. Soc. 155 (2008) B187.

[16] S. von Kraemer, K. Wikander, G. Lindbergh, A. Lundblad, A.E.C. Palmqvist, Evaluation of $\mathrm{TiO}_{2}$ as catalyst support in $\mathrm{Pt}-\mathrm{TiO}_{2} / \mathrm{C}$ composite cathodes for the proton exchange membrane fuel cell, J. Power Sources 180 (2008) 185

[17] G. Liu, H. Zhang, Y. Zhai, Y. Zhang, D. Xu, Z. Shao, $\mathrm{Pt}_{4} \mathrm{ZrO}_{2} /$ C cathode catalyst for improved durability in high temperature PEMFC based on $\mathrm{H}_{3} \mathrm{PO}_{4}$ doped PBI, Electrochem. Commun. 9 (2007) 135

[18] J. Shim, C.-R. Lee, H.-K. Lee, J.-S. Lee, E. Cairns, Electrochemical characteristics of Pt-WO $\mathrm{WO}_{3} / \mathrm{C}$ and $\mathrm{Pt}-\mathrm{TiO}_{2} / \mathrm{C}$ electrocatalysts in a polymer electrolyte fuel cell, J. Power Sources 102 (2001) 172

[19] S. Trasatti, Physical electrochemistry of ceramic oxides, Electrochim. Acta 36 (1991) 225.

[20] H.P. Dhar, A unitized approach to regenerative solid polymer electrolyte fuelcells, J. Appl. Electrochem. 23 (1993) 32.

[21] L.L. Swette, A.B. LaConti, S.A. McCatty, Proton-exchange membrane regenerative fuel-cells, J. Power Sources 47 (1994) 343.

[22] T. Ioroi, N. Kitazawa, K. Yasuda, Y. Yamamoto, H. Takenaka, Iridium oxide/platinum electrocatalysts for unitized regenerative polymer electrolyte fuel cells, J. Electrochem. Soc. 147 (2000) 2018

[23] T. Ioroi, N. Kitazawa, K. Yasuda, Y. Yamamoto, H. Takenaka, $\mathrm{IrO}_{2}$-deposited Pt electrocatalysts for unitized regenerative polymer electrolyte fuel cells, J. Appl. Electrochem. 31 (2001) 1179.

[24] T. Ioroi, K. Yasuda, Z. Siroma, N. Fujiwara, Y. Miyazaki, Thin film electrocatalyst layer for unitized regenerative polymer electroltye fuel cells, J. Power Sources $112(2002) 583$

[25] S.-D. Yim, W.-Y. Lee, Y.-G. Yoon, Y.-J. Sohn, G.-G. Park, T.-H. Yang, C.-S. Kim, Optimization of bifunctional electrocatalyst for PEM unitized regenerative fue cell, Electrochim. Acta 50 (2004) 713

[26] C. D’Urso, L. Morales, A. Di Blasi, V. Baglio, R. Ornelas, G. Orozco, L.G. Arriaga, V. Antonucci, A.S. Arico, Preparation and application of $\mathrm{IrO}_{2} / \mathrm{Pt}$ electrocatalyst for regenerative fuel cells, ECS Trans. 11 (2007) 191.

[27] H.-Y. Jung S. Park, B.N. Popov, Electrochemical studies of an unsupported PtIr electrocatalyst as a bifunctional oxygen electrode in a unitized regenerative fuel cell, J. Power Sources 191 (2009) 357

[28] H.-Y.Jung, P. Ganesan, B.N. Popov, Development of high durability bi-functional oxygen electrode for unitized regenerative fuel cell (URFC), ECS Transactions 25 (2009) 1261

[29] E. Slavcheva, I. Radev, G. Topalov, E. Budevski, Sputtered electrocatalysts for PEM electrochemical energy converters, Electrochim. Acta 53 (2007) 362.

[30] G. Chen, H. Zhang, H. Zhong, H. Ma, Gas diffusion layer with titanium carbide for a unitized regenerative fuel cell, Electrochim. Acta 55 (2010) 8801

[31] Y. Ma, P.B. Balbuena, B. Perla, Role of iridium in Pt-based alloy catalysts for the ORR: Surface adsorption and stabilization studies, J. Electrochem. Soc. 157 (2010) B959

[32] J-G. Oh, W. Hee Lee, H. Kim, The inhibition of electrochemical carbon corrosion in polymer electrolyte membrane fuel cells using iridium nanodendrites, Int. J. Hydrogen Energy 37 (2012) 2455.

[33] P. Holt-Hindle, Q. Yi, G. Wu, K. Koczkur, A. Chen, Electrocatalytic activity of nanoporous Pt-Ir materials toward methanol oxidation and oxygen reduction, J. Electrochem. Soc. 155 (2008) K5

[34] T. Ioroi, K. Yasuda, Platinum-iridium alloys as oxygen reduction electrocatalysts for polymer electrolyte fuel cells, J. Electrochem. Soc. 152 (2005) A1917.

[35] S.J. Hwang, S.J. Yoo, T.-Y. Jeon, K.-S. Lee, T.-H. Lim, Y.-E. Sung, S.-K. Kim, Facile synthesis of highly active and stable Pt-Ir/C electrocatalysts for oxygen reduction and liquid fuel oxidation reaction, Chem. Commun. 46 (2010) 8401.

[36] I. Radev, G. Topalov, E. Lefterova, G. Ganske, U. Schnakenbeg, G. Tsotridis, E. Slavcheva, Optimization of platinum/iridium ratio in thin sputtered films for PEMFC cathodes, Int. J. Hydrogen Energy 37 (2012) 7730.

[37] R.R. Adzic, J. Zhang, K. Sasaki, M.B. Vukmirovic, M. Shao, J.X. Wang, A.U. Nilekar, M. Mavrikakis, J.A. Valerio, F. Uribe, Platinum monolayer fuel cell electrocatalysts, Top. Catal. 46 (2007) 249

[38] C.H. Chang, T.S. Yuen, Y. Nagao, H. Yugami, Catalytic activity of carbonsupported iridium oxide for oxygen reduction reaction as a Pt-free catalyst in polymer electrolyte fuel cell, Soid State Ionics 197 (2011) 49

[39] C.H. Chang, T.S. Yuen, Y. Nagao, H. Yugami, Electrocatalytic activity of iridium oxide nanoparticles coated on carbon for oxygen reduction as cathode catalyst in polymer electrode fuel cell, J. Power Sources 195 (2010) 5938. 
[40] M. Wesselmark, B. Wickman, C. Lagergren, G. Lindbergh, Electrochemical performance and stability of thin film electrodes with metal oxides in polymer electrolyte fuel cells, Electrochim. Acta 55 (2010) 7590.

[41] E.N. El Sawy, V.I. Birss, Nano-porous iridium and iridium oxide thin films formed by high efficiency electrodeposition, J. Mater Chem. 19 (2009) 8244.

[42] J. Mozota, B.E. Conway, Surface and bulk processes at oxidized iridium electrodes. 1. Monolayer stage and transition to reversible multilayer oxide film behavior, Electrochim. Acta 28 (1983) 1.

[43] J.F. Moulder, W.F. Stickle, P.E. Sobol, K.D. Bomben, in: J. Chastain (Ed.), Handbook of X-ray Photoelectron Spectroscopy, PerkinElmer Corporation, Minneapolis, 1992.

[44] J. Ihonen, F. Jaouen, G. Lindbergh, G. Sundholm, A novel polymer electrolyte fuel cell for laboratory investigations and in-situ contact resistance measurements, Electrochim. Acta 46 (2001) 2899.

[45] S. Gottesfeld, S. Srinavasan, Electrochemical and optical studies of thick oxide layers on iridium and their electrocatalytic activities for oxygen evolution reaction, J. Electroanal. Chem. 66 (1978) 89.
[46] C. Bock, V.I. Birss, Anion and water involvement in hydrous Ir oxide redox reactions in acidic solutions, J. Electroanal. Chem. 475 (1999) 20.

[47] I.A. Lervik, M. Tsypkin, L.-E. Owe, S. Sunde, Eletronic structure vs. electrocatalytic activity of iridium oxide, J. Electroanal. Chem. 645 (2010) 135-142.

[48] L. Ouattara, S. Fierro, O. Frey, M. Koudelka, C. Comninellis, Electrochemical comparison of $\mathrm{IrO}_{2}$ prepared by anodic oxidation of pure iridium and $\mathrm{IrO}_{2}$ prepared by thermal decomposition of $\mathrm{H}_{2} \mathrm{IrCl}_{6}$ precursor solution, J. Appl. Electrochem. 39 (2009) 1361.

[49] D.A.J. Rand, R. Woods, Cyclic voltammetric studies on iridium electrodes in sulfuric acid solutions - Nature of oxygen layer and metal dissolution, Electroanal. Chem. Interfacial Electrochem. 55 (1974) 375.

[50] S. Hackwood, L.M. Schiavone, W.C. Dautremont-Smith, G. Beni, Anodic evolution of oxygen on sputtered iridium oxide-films, J. Electrochem. Soc. 128(1981) 2569.

[51] A. Chen, D.J. La Russa, B. Miller, Effect of the iridium oxide thin film on the electrochemical activity of platinum nanoparticles, Langmuir 20 (2004) 9695. 